Supporting Information

\title{
Photochemical Hydrogenation of $\pi$-Conjugated Bridging Ligands in Photofunctional Multinuclear Complexes
}

Yasuomi Yamazaki, Akinari Umemoto, and Osamu Ishitani*

Department of Chemistry, Graduate School of Science and Engineering, Tokyo Institute of Technology, 2-12-1-NE-1, Ookayama, Meguro-ku, Tokyo, 152-8550, Japan 


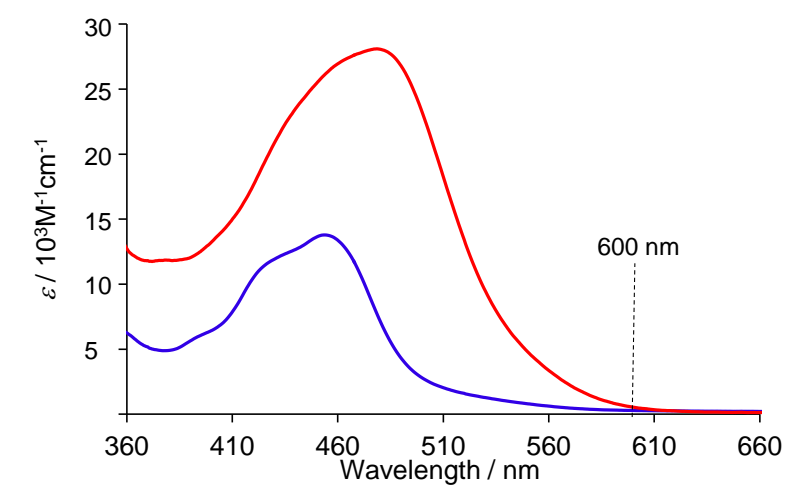

Figure S1. Absorption spectra of $\mathbf{R u}(\mathbf{C}=\mathbf{C}) \mathbf{R e}^{3+}(\mathrm{red})$ and $\left[\mathrm{Ru}(\mathrm{bpy})_{2}(\mathrm{dmb})\right]^{2+}$ (blue) measured in acetonitrile.

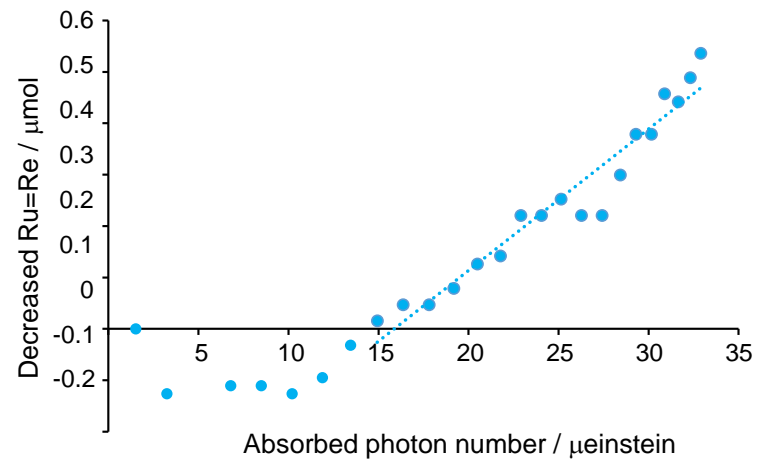

Figure S2. The relationship between absorbed photon number and amount of $\mathbf{R u}(\mathbf{C}=\mathbf{C}) \mathbf{R e}^{3+}$ reacted. The amount was estimated from the differential absorbance at $600 \mathrm{~nm}$ divided by the differential molar extinction absorbance. In order to increase absorbance at $600 \mathrm{~nm}$, the initial concentration of $\mathbf{R u}(\mathbf{C}=\mathbf{C}) \mathbf{R e}^{3+}$ was changed to $0.12 \mathrm{mM}$. From the slope of the fitting curve illustrated as the dotted line, the quantum yield was estimated at $3 \%$.

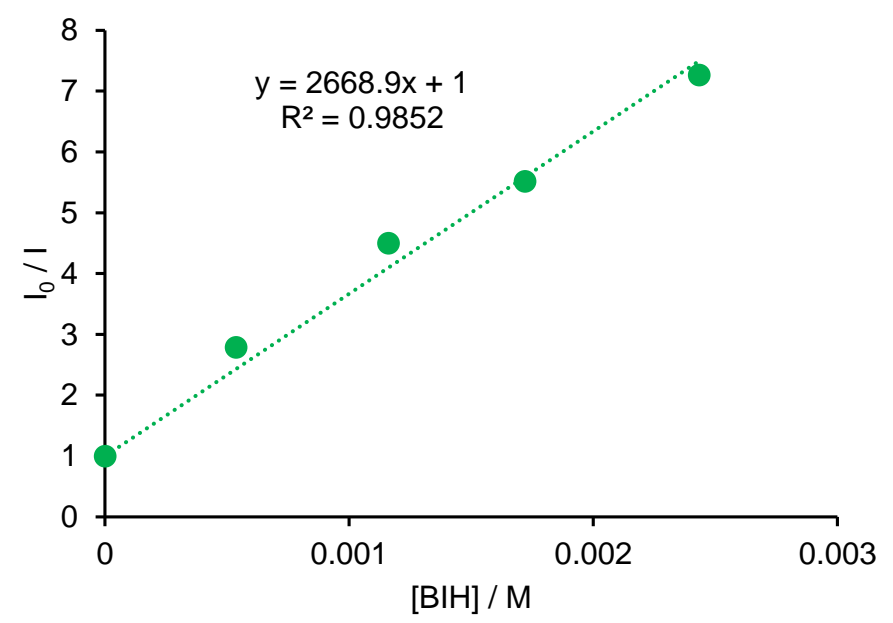

Figure S3. Stern-Volmer plots using $\mathrm{BIH}$ and $\mathbf{R u}(\mathbf{C}=\mathbf{C}) \mathbf{R e}^{3+}$. The solvent was $\mathrm{MeCN}-$ pyridine- $\mathrm{CF}_{3} \mathrm{COOH}$ mixed solvent $(3: 1: 0.1 \mathrm{v} / \mathrm{v} / \mathrm{v})$. The excitation wavelength was $510 \mathrm{~nm}$, and the detection wavelength was $725 \mathrm{~nm}$.

*The emission decay curve of $\mathbf{R u}(\mathbf{C}=\mathbf{C}) \mathbf{R e}^{3+}$ was fitted by double exponential functions $\left(A_{1} \exp \left(-\mathrm{t} / \tau_{1}\right)+A_{2} \exp (-\mathrm{t} /\right.$ $\left.\left.\tau_{2}\right), \tau_{1}=1881 \mathrm{~ns}\left(A_{1}=72 \%\right), \tau_{2}=1071 \mathrm{~ns}\left(A_{2}=28 \%\right)\right)$. 


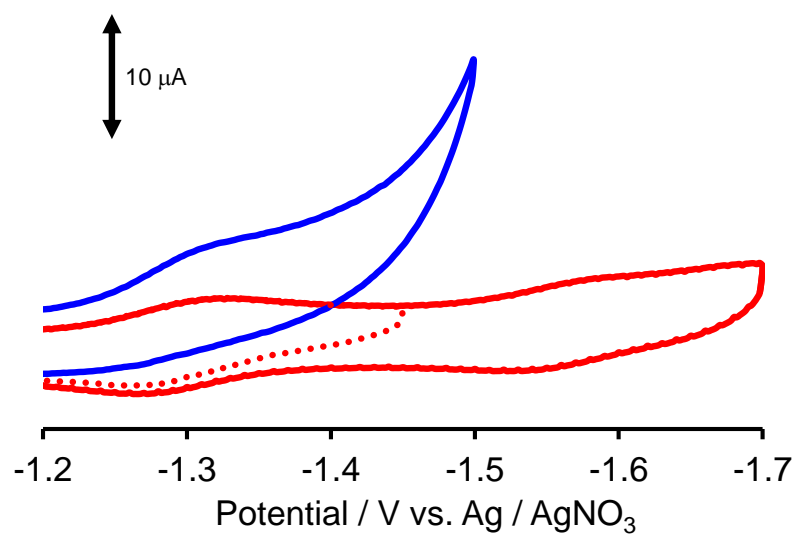

Figure S4. Cyclic voltammograms of $\mathbf{R u}(\mathbf{C}=\mathbf{C}) \mathbf{R e}^{3+}(0.01 \mathrm{mM})$ measured in $\mathrm{MeCN}$ (red line) and $\mathrm{MeCN}$-pyridine- $\mathrm{CF}_{3} \mathrm{COOH}\left(3: 1: 0.1 \mathrm{v} / \mathrm{v} / \mathrm{v}\right.$, blue line) containing $\mathrm{NEt}_{4} \mathrm{BF}_{4}(0.1 \mathrm{M})$ under an $\mathrm{Ar}$ atmosphere. The sweep scan rate was $200 \mathrm{mV} \mathrm{s}^{-1}$.

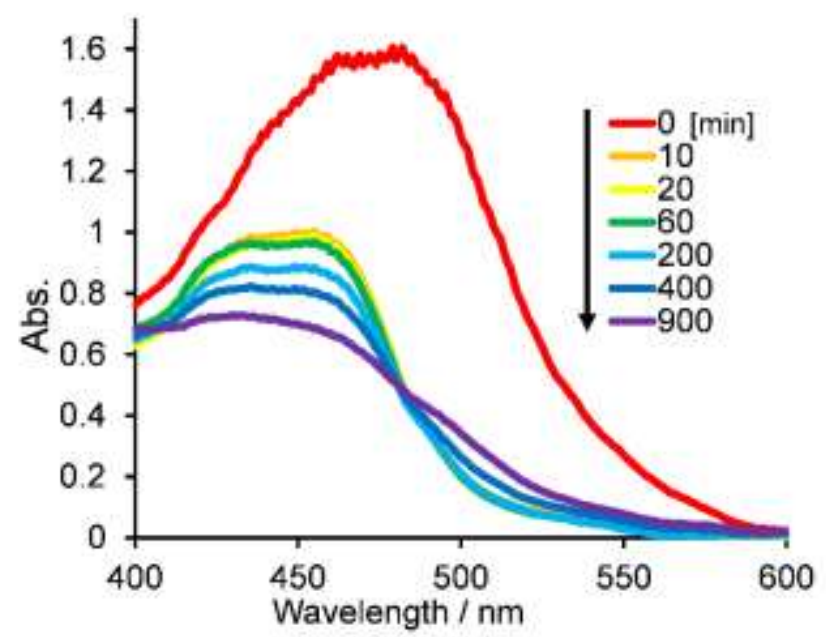

Figure S5. Absorption spectral changes of the $\mathrm{MeCN}$-pyridine mixed solution containing $\mathbf{R u}(\mathbf{C}=\mathbf{C}) \mathbf{R e}^{\mathbf{3 +}}$, $\mathrm{CF}_{3} \mathrm{COOH}$, and $\mathrm{BIH}$ during irradiation at $\lambda_{\mathrm{ex}}=480 \mathrm{~nm}$. 


\section{(a) $[(\mathrm{EtO}) \operatorname{Re}(\mathrm{CH}-\mathrm{CH}) \operatorname{Re}(\mathrm{Et})]^{2+}$}

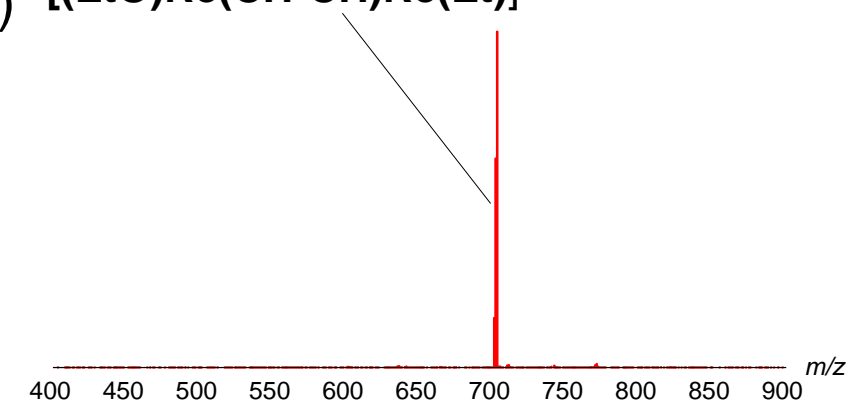

(b)

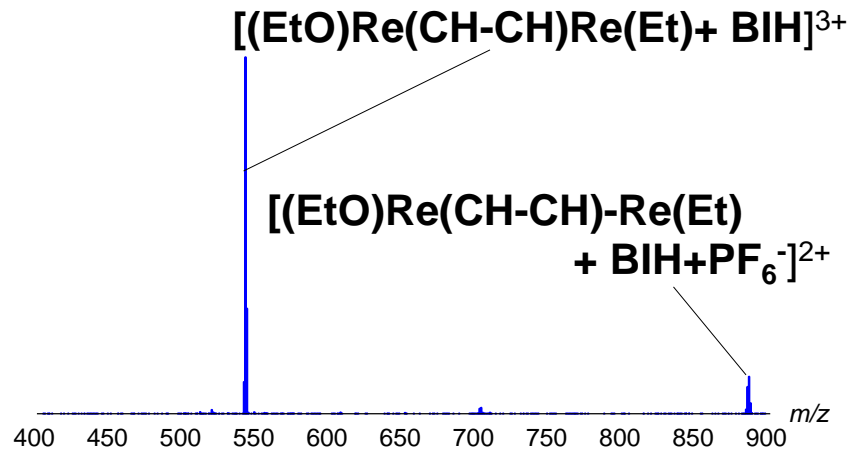

Figure S6. The ESI-mass spectra of the products contained in (a) the first yellow fraction and (b) the second yellow fraction of the ion exchange chromatography conducted after the hydrogenation reaction of $(\operatorname{EtO}) \operatorname{Re}(\mathrm{C}=\mathrm{C}) \operatorname{Re}(\mathrm{Et})^{2+}$.

*Relatively large amount of byproducts, probably derived from side reaction between photochemically-reduced species of $(\mathbf{E t O}) \operatorname{Re}(\mathbf{C}=\mathbf{C}) \operatorname{Re}(\mathbf{E t})^{2+}$ and the oxidant of BIH, were observed in the third fraction of the ion exchange chromatography as shown in Fig. S6 (first fraction: BIH and their oxidants, second fraction: $(\mathbf{E t O}) \operatorname{Re}(\mathbf{C}=\mathbf{C}) \operatorname{Re}(\mathbf{E t})^{2+}$, third fraction: BIH adducts). The BIH adducts could be easily removed by chromatography because they had different charges than $(\mathbf{E t O}) \operatorname{Re}(\mathbf{C}=\mathbf{C}) \operatorname{Re}(\mathbf{E t})^{2+}$. The byproduct BIH adducts were obtained with a $29 \%$ isolation yield. 

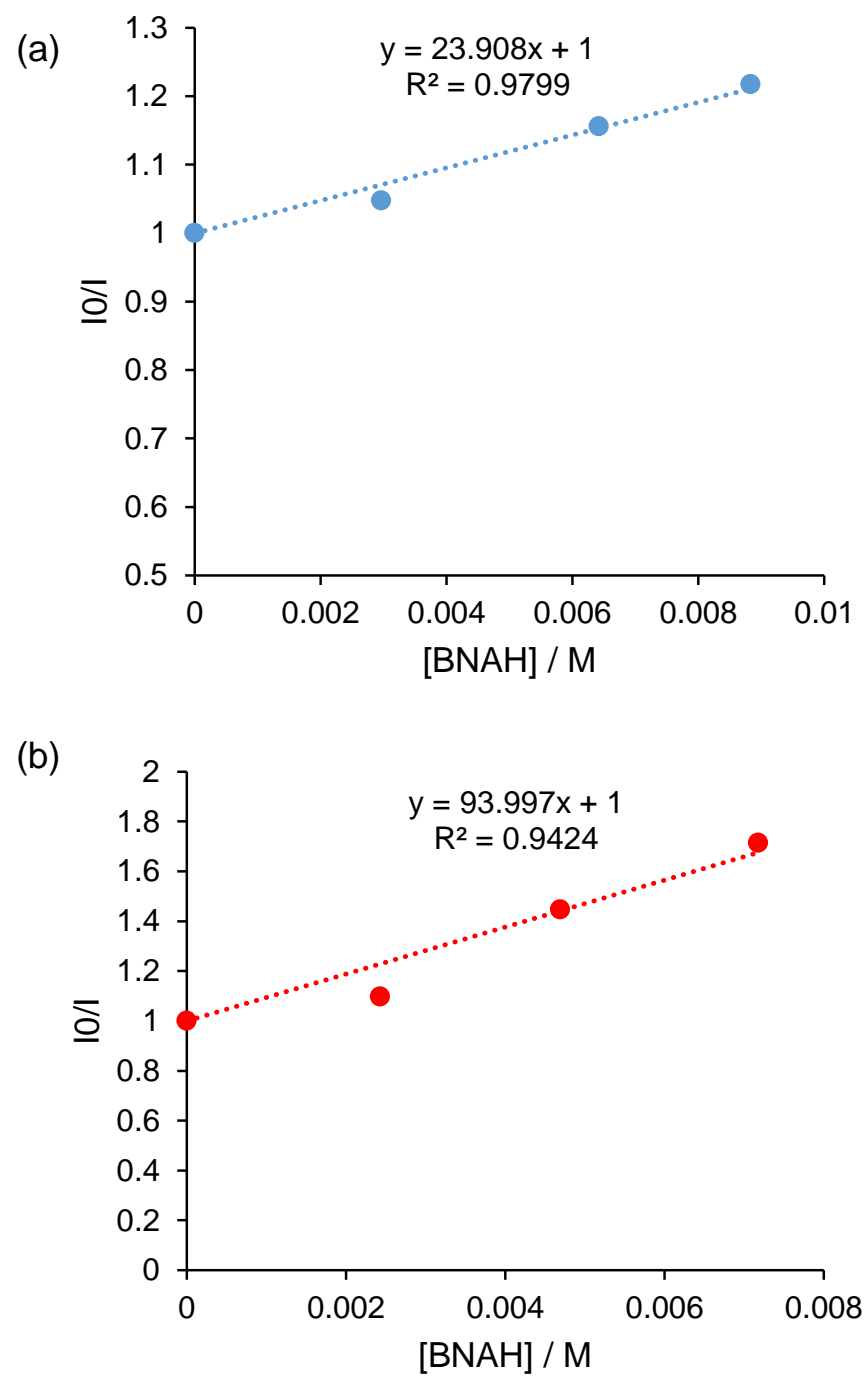

Figure S7. Stern-Volmer plots using (a) $\mathbf{R u}(\mathbf{C H}-\mathbf{C H}) \operatorname{Re}(\mathbf{C H}-\mathbf{C H}) \mathbf{R u}^{5+}$ and (b) $\operatorname{Ru}(\mathbf{C}=\mathbf{C}) \operatorname{Re}(\mathbf{C}=\mathbf{C}) \mathbf{R u}^{5+}$. The excitation wavelength was $530 \mathrm{~nm}$, and the detection wavelength was the emission maximum of the respective compound shown in Table S1 

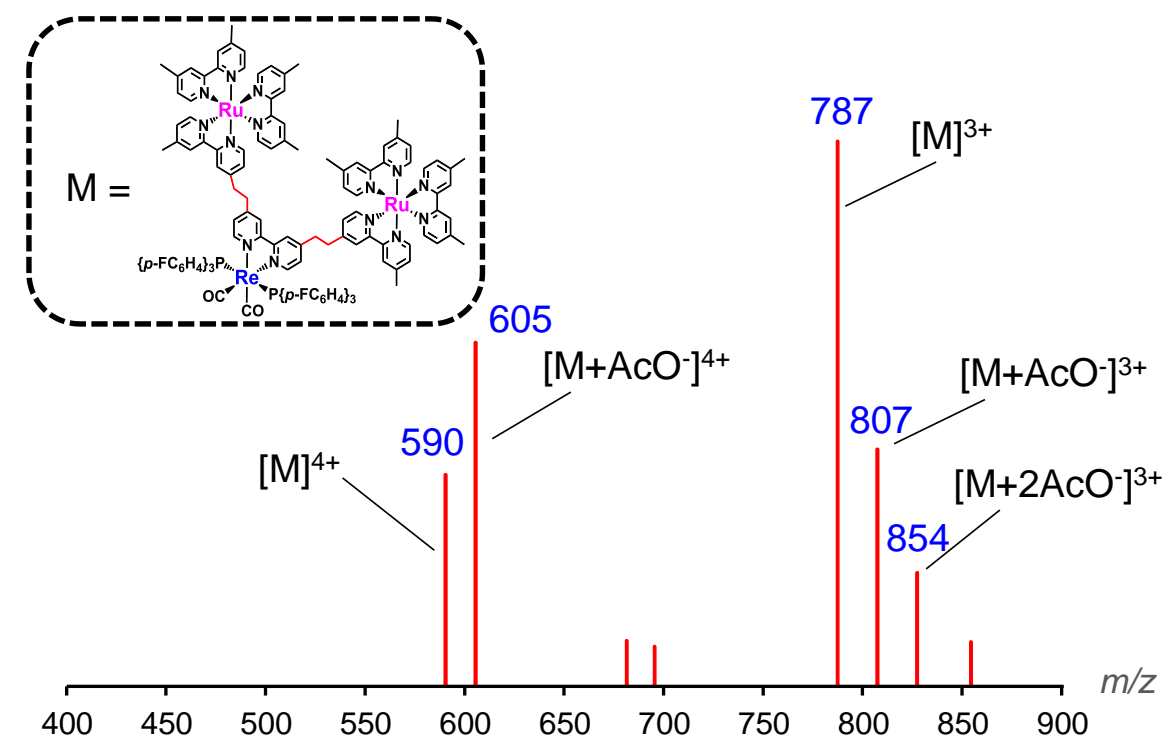

Figure S8. ESI-mass spectrum of the eluate at the first peak ( $\mathrm{RT}=33 \mathrm{~min}$ ) shown in Fig. 6 of SEC separated from the reaction solution before photocatalysis using $\operatorname{Ru}(\mathbf{C H}-\mathbf{C H}) \operatorname{Re}(\mathbf{C H}-\mathbf{C H}) \mathbf{R u}^{5+}$. Some of the peaks are attributed to the reduced form of $\operatorname{Ru}(\mathbf{C H}-\mathbf{C H}) \operatorname{Re}(\mathbf{C H}-\mathbf{C H}) \mathbf{R u}^{5+}$, i.e., $\mathrm{M}^{4+}$ and $\mathrm{M}^{3+}$. The eluent of the SEC was an $\mathrm{MeCN}-\mathrm{MeOH}(1: 1 \mathrm{v} / \mathrm{v})$ mixed solution containing $0.05 \mathrm{mM} \mathrm{NH}_{4} \mathrm{OAc}$.

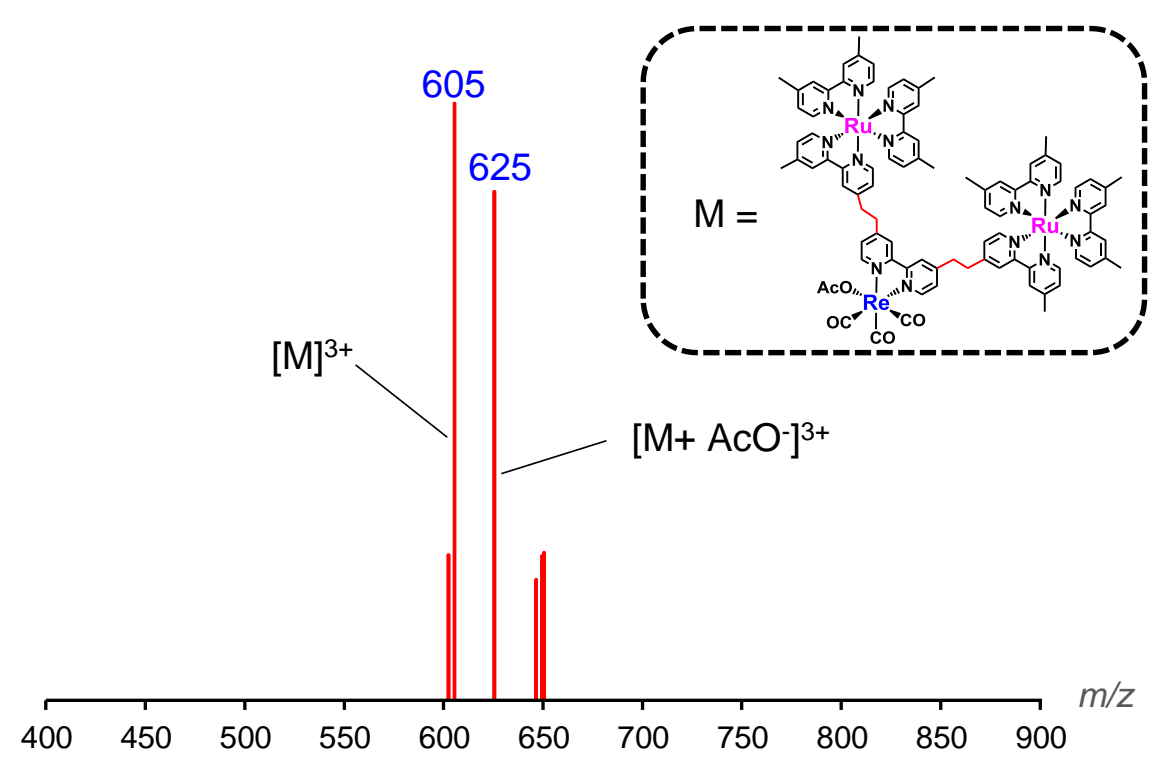

Figure S9. ESI-mass spectrum of the eluate at the second peak $(\mathrm{RT}=34 \mathrm{~min})$ shown in Fig. 6 of SEC, separated from the reaction solution after $1 \mathrm{~h}$ of photocatalysis using $\mathbf{R u}(\mathbf{C H}-\mathrm{CH}) \operatorname{Re}(\mathbf{C H}-\mathbf{C H}) \mathbf{R u}^{5+}$. Some of the peaks are attributed to the reduced form of $\mathbf{R u}(\mathbf{C H}-\mathbf{C H}) \mathbf{R e} \mathbf{e}^{\prime}(\mathbf{C H}-\mathbf{C H}) \mathbf{R u}$, i.e., $\mathbf{M}^{3+}$. The eluent of the SEC was an $\mathrm{MeCN}-\mathrm{MeOH}(1: 1 \mathrm{v} / \mathrm{v})$ mixed solution containing $0.05 \mathrm{mM} \mathrm{NH}_{4} \mathrm{OAc}$. 


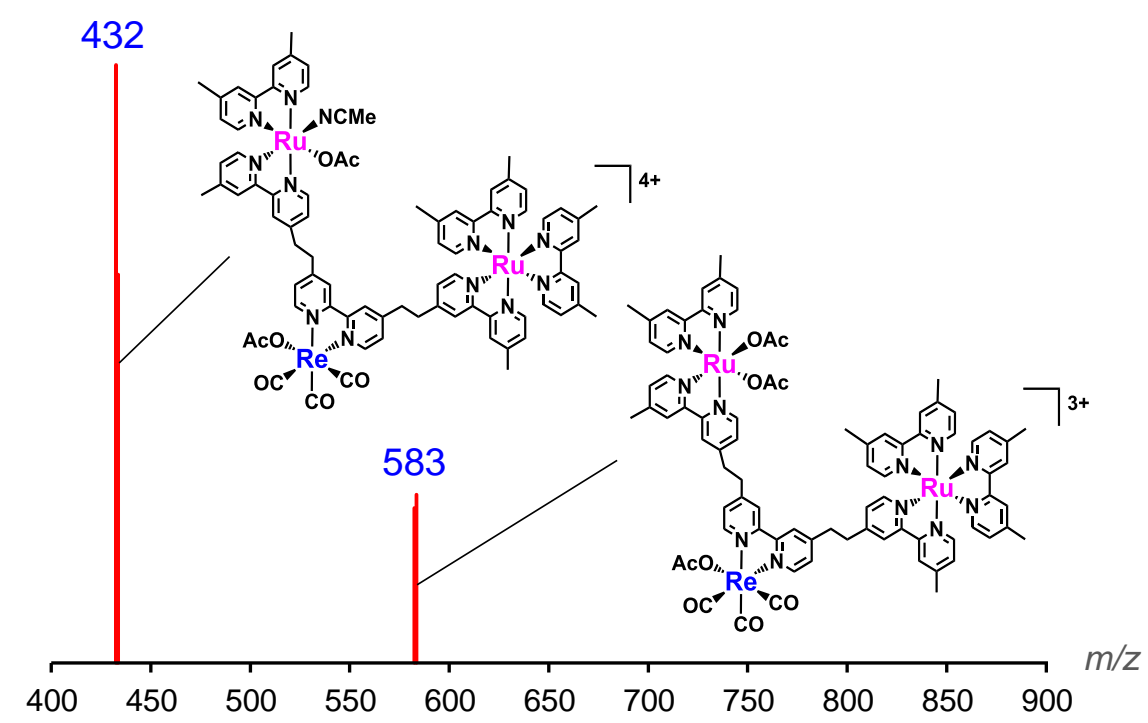

Figure S10. ESI-mass spectrum of the eluate at the third peak $(\mathrm{RT}=35-37 \mathrm{~min})$ shown in Fig. 6 of SEC separated from the reaction solution after $1 \mathrm{~h}$ of photocatalysis using $\mathbf{R u}(\mathbf{C}=\mathbf{C}) \mathbf{R e}(\mathbf{C}=\mathbf{C}) \mathbf{R} \mathbf{u}^{5+}$. The eluent of the $\mathrm{SEC}$ was an $\mathrm{MeCN}-\mathrm{MeOH}(1: 1 \mathrm{v} / \mathrm{v})$ mixed solution containing $0.05 \mathrm{mM} \mathrm{NH}_{4} \mathrm{OAc}$.

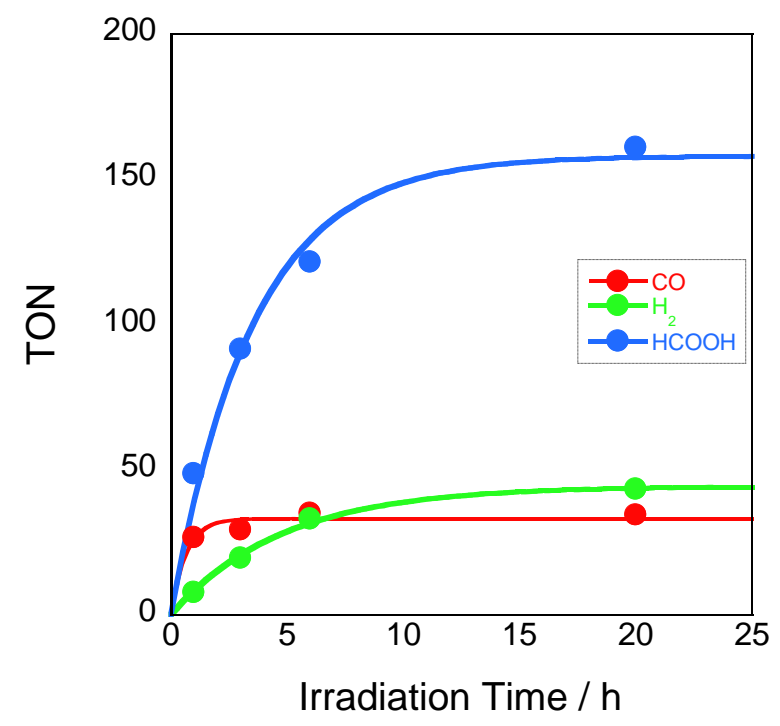

Figure S11. Time courses of TON of reduction products, i.e., $\mathrm{CO}$ (red), $\mathrm{H}_{2}$ (green) and $\mathrm{HCOOH}$ (blue), during photocatalytic reaction $\left(20 \mathrm{~h}, \lambda_{\mathrm{ex}}>500 \mathrm{~nm}\right)$ using a mixture of DMF and triethanolamine $(5: 1 \mathrm{v} / \mathrm{v})$ containing and $0.1 \mathrm{M}$ BNAH, and mixture of $0.1 \mathrm{mM}$ corresponding $\mathrm{Ru}(\mathrm{II})$ mononuclear complex $\left(\left[\mathrm{Ru}(\mathrm{dmb})_{2}(\mathrm{vbpy})\right]\left(\mathrm{PF}_{6}\right)_{2}\right)$ and $0.05 \mathrm{mM}\left[\mathrm{Re}(\mathrm{dmb})(\mathrm{CO})_{2}\left\{\mathrm{P}\left(p-\mathrm{C}_{6} \mathrm{H}_{4} \mathrm{~F}\right)_{3}\right\}_{2}\right]^{+}$. Formate was detected as the main product in this mixture system. 
Table S1. Photophysical properties of the trinuclear complexes. ${ }^{2}$

\begin{tabular}{|c|c|c|c|c|c|}
\hline Complex & $\begin{array}{c}\lambda_{\mathrm{abs}} / \mathrm{nm} \\
\left(\varepsilon / 10^{3} \mathrm{M}^{-1} \mathrm{~cm}^{-1}\right)\end{array}$ & $\lambda_{\mathrm{em}}^{\max } / \mathrm{nm}$ & $\Phi_{\mathrm{em}}$ & $\begin{array}{l}\tau_{1} / \mathrm{ns}^{\mathrm{d}} \\
(\mathrm{A} / \%)\end{array}$ & $\begin{array}{l}\tau_{2} / \mathrm{ns}^{\mathrm{d}} \\
(\mathrm{A} / \%)\end{array}$ \\
\hline \multirow{3}{*}{$\operatorname{Ru}(C=C) \operatorname{Re}(C=C) R^{5+}$} & $495(52.3)$ & \multirow{3}{*}{$743^{\mathrm{b}}$} & \multirow{3}{*}{$0.03^{\mathrm{b}}$} & \multirow{3}{*}{$1112(94)^{b}$} & \multirow{3}{*}{$471(6)^{\mathrm{b}}$} \\
\hline & $341(\mathrm{sh}, 50.7)$ & & & & \\
\hline & $287(156)$ & & & & \\
\hline \multirow{2}{*}{$\operatorname{Ru}(\mathrm{CH}-\mathrm{CH}) \operatorname{Re}(\mathrm{CH}-\mathrm{CH}) \mathrm{Ru}^{5+}$} & $459(31.5)$ & \multirow{2}{*}{$635^{\mathrm{c}}$} & \multirow{2}{*}{$0.11^{\mathrm{c}}$} & \multirow{2}{*}{$851(100)^{\mathrm{c}}$} & \\
\hline & $288(170)$ & & & & \\
\hline
\end{tabular}

${ }^{\mathrm{a}}$ Measured in MeCN. ${ }^{\mathrm{b}}$ Excitation wavelength: $456 \mathrm{~nm} .{ }^{\mathrm{c}}$ Excitation wavelength: $510 \mathrm{~nm}$. (d) Detected at each wavelength of the emission maximum.

Table S2. Redox Potentials of the trinuclear complexes. ${ }^{\text {a }}$

\begin{tabular}{|c|c|c|c|c|c|c|c|c|}
\hline \multirow{2}{*}{ Complex } & \multicolumn{8}{|c|}{$E(\Delta E / \mathrm{mV}) / \mathrm{V}$ vs. $\mathrm{Ag} / \mathrm{AgNO}_{3}$} \\
\hline & $\operatorname{Re}^{\mathrm{II} / \mathrm{I}}$ & $\mathrm{Ru}^{\mathrm{III} / \mathrm{II}}$ & & & & & & \\
\hline \multirow{2}{*}{$\operatorname{Ru}(C=C) \operatorname{Re}(C=C) R^{5+}$} & & +0.84 & -1.24 & -1.43 & -1.67 & -1.73 & -1.93 & -2.18 \\
\hline & +1.21 & (91) & $(69)$ & (69) & (64) & (79) & (98) & $(85)$ \\
\hline \multirow{2}{*}{$\operatorname{Ru}(\mathrm{CH}-\mathrm{CH}) \operatorname{Re}(\mathrm{CH}-\mathrm{CH}) \mathbf{R u}^{5+}$} & $17^{\mathrm{b}}$ & +0.82 & -1.63 & -1.72 & -1.93 & -2.19 & & \\
\hline & +1.17 & $(61)$ & (58) & (69) & $(67)$ & $(72)$ & & \\
\hline
\end{tabular}

${ }^{\mathrm{a}}$ Measured in $\mathrm{MeCN}$ containing $\mathrm{Et}_{4} \mathrm{NBF}_{4}(0.1 \mathrm{M})$ with the scan rate of $200 \mathrm{mV} \mathrm{s}^{-1} .{ }^{\mathrm{b}}$ Peak potential. 